Fisioter Bras 2019;20(5):681-3

https://doi.org/10.33233/fb.v20i5.3275

\title{
OPINIÃO \\ Como a Saúde Digital transformará a Fisioterapia
}

\author{
Guilherme Rabello
}

Engenheiro pela Escola Politécnica da USP, Gerente Comercial e de Inteligência de Mercado do InovalnCor (núcleo de inovação do Instituto do Coração-InCor e da Fundação Zerbini), Membro do Comitê Executivo de Inovação do Hospital das Clínicas da Faculdade de Medicina da USP, Presidente do Conselho de Administração da Fundação para Segurança do Paciente (FSP), Professor do MBA HealthTech na FIAP-SP, Professor da Faculdade de Medicina da USP, disciplina de "Inovação e Empreendedorismo na Saúde"

Correspondência: Rua Dr. Enéas de Carvalho Aguiar, 255 Cerqueira César 05402-000 São Paulo SP

grabello.inovaincor@zerbini.org.br

Uma das histórias mais significativas na revolução industrial do século passado é a protagonizada por Henry Ford, criador da empresa de automóveis Ford. O famoso carro Modelo T era o vigésimo projeto da empresa. Mas Henry Ford havia criado algo diferente - um novo modelo de negócio com uma nova forma produtiva, a linha de montagem em série, que permitiu diminuir em muito o custo de seus automóveis e transformar seu carro no mais conhecido da época, bem como escrever uma das páginas da história da Revolução Industrial moderna.

Porém, Ford não chegou ao sucesso sem enfrentar grandes dificuldades. Transformar uma indústria que ainda estava nascendo - a automotiva - era em si mesmo um enorme obstáculo. Em uma ocasião, falando sobre os problemas com os quais se deparava ao desenvolver seu modelo de fabricação de carros, ele disse: "Não encontro defeitos, encontro soluções. Qualquer um sabe queixar-se?". Sim, queixar-se das dificuldades era simples miopia, mas enxergar as soluções era ter visão de horizonte - uma enorme diferença entre sucesso e fracasso! Henry Ford como inovador teve Visão.

A história da Fisioterapia começa a ser escrita a alguns milênios. O termo Fisioterapia vem das palavras gregas: "Physis", que significa "Natureza" e "Therapeia", que quer dizer "Tratamento", podendo ser definida como a ciência que estuda o movimento humano e que utiliza recursos físicos no tratamento e cura.

Segundo estudiosos do assunto, o costume de se utilizar formas de movimento como recurso terapêutico remonta há vários séculos antes da nossa era cristã. Naquela ocasião, acreditava-se que o uso da ginástica (palavra originada do grego gymnádzein, que tem por tradução aproximada "treinar" e, em sentido literal, "exercitar-se nu") estava unicamente nas mãos dos sacerdotes e que era empregada somente com fins terapêuticos, no tratamento de disfunções orgânicas já existentes na pessoa.

\section{Mas como a Saúde Digital entra em cena na Fisioterapia?}

Se considerarmos que os objetivos da Fisioterapia são estudar o movimento humano e utilizar recursos físicos no tratamento e cura, então os novos recursos da tecnologia digital que apareceram nas últimas décadas se tornam grandes ferramentas para transformar a Fisioterapia tradicional como a conhecemos (e alguns até acham monótona e ineficaz) em uma versão dinâmica e capaz de engajar o paciente e fornecer dados vitais para os profissionais fisioterapeutas e médicos poderem avaliar o progresso dos pacientes e as melhores condutas clínicas a serem aplicadas! Bem-vindo a Fisioterapia 4.0!

Há uma revolução literal em andamento no campo da Fisioterapia, com a inclusão das mais diversas ferramentas digitais de computação 3D voltadas para o estudo do movimento do corpo (cinesiologia), na adoção de Realidade Virtual para exercícios terapêuticos, no uso de aplicativos com interatividade para engajamento e educação do paciente nos exercícios, até o 
uso de wearables para rastrear e medir as atividades de cada paciente visando a personalização do tratamento.

A Saúde Digital verdadeiramente abriu a caixa de Pandora na Fisioterapia!

Veja alguns exemplos do que citamos acima, dentre os muitos produtos, soluções e serviços que estão aparecendo quase que diariamente no mercado global da Saúde:

1) Computação 3D para análise de movimentos - assim como temos o uso desta tecnologia para criar personagens animados nos desenhos de Hollywood, da mesma forma esta tecnologia tem sido aplicada para estudar o movimento de pacientes e poder ajudá-los na recuperação de disfunções motoras e posturais.

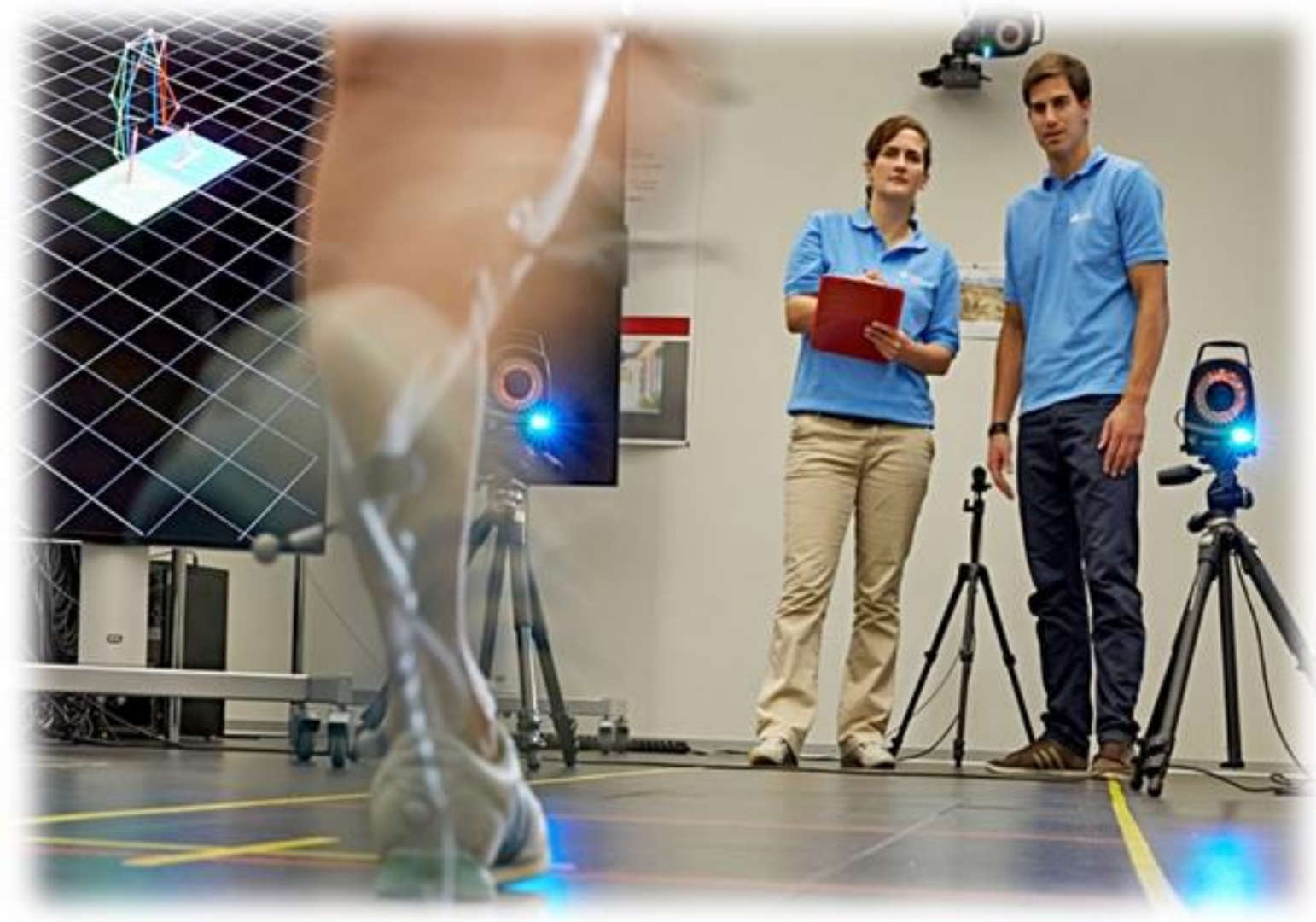

Figura 1 - Análise de movimento por computação 3D.

2) Realidade Virtual para tratamento fisioterápico - Mais do que uma tecnologia que é utilizada nos games digitais modernos para aumentar a sensação de realidade dos jogos, a Realidade Virtual (ou VR) tem diversas utilidades em outras áreas como simulação de treinamento de pilotos, desenvolvimento de projetos complexos de engenharia, etc. Mas na Fisioterapia sua aplicação pode ajudar muito os pacientes ao realizar os exercícios e para os profissionais poderem medir o progresso da terapia indicada.

3) Aplicativos de exercícios fisioterápicos - hoje existem aplicativos para quase tudo, e na Fisioterapia não seria diferente. É claro que precisamos saber se os Apps que escolhemos são adequados e seguem os melhores padrões científicos e médicos, mas há boas opções disponíveis.

4) Wearables de rastreamento físico para análise de dados e avaliação clínica - Como em muitas situações aonde precisamos ter dados para podermos analisar a performance dos produtos e sistemas (exemplos: Fórmula 1, linha de produção de fábrica, centros de processamento de dados, bancos, etc), a Internet das Coisas trouxe uma grande quantidade de wearables para uso pessoal que nos permite gerar informações relevantes no tratamento clínico, como no caso de pessoas com problemas crônicos de dores. Mais do que apenas wearables, alguns produtos se 
tornam ferramentas de gestão de recursos humanos e auxiliam na prevenção e melhoria do condicionamento físico das pessoas.

Como podem ver, há uma revolução em andamento no modo como a Fisioterapia tradicional se transformará na Fisioterapia 4.0! O mesmo que Henry Ford fez na indústria automotiva ao modificar a Visão do setor para produzir carros, a Saúde Digital fará da mesma maneira em como a Fisioterapia capacitará seus profissionais no atendimento, acompanhamento e análise dos pacientes, que por outro lado estarão mais engajados em seu próprio tratamento. No final, o resultado esperado é um melhor desfecho na Saúde do paciente!

\section{Referências}

1. Yang J, Wei Q, Ge Y, Meng L, Meidan Zhao. Smartphone-based remote selfmanagement of chronic low back pain: a preliminary study. Journal of Healthcare Engineering 2019: Article ID 4632946. https://doi.org/10.1155/2019/4632946

2. Zanona AF, de Souza RF, Aidar FJ, de Matos DG, Santos KMB, Paixão MDC, Sampaio PYS, Almeida Junior H, Monte-Silva KK. Use of virtual rehabilitation to improve the symmetry of body temperature, balance, and functionality of patients with stroke sequelae. Ann Neurosci 2019;25(3):166-73. https://doi.org/10.1159/000488581

3. Mohammadi R, Semnani AV, Mirmohammadkhani M, Grampurohit N. Effects of virtual reality compared to conventional therapy on balance poststroke: a systematic review and meta-analysis. J Stroke Cerebrovasc Dis 2019;28(7):1787-98.

https://doi.org/10.1016/j.jstrokecerebrovasdis.2019.03.054 